\title{
AVALIAÇÃO DA UTILIZAÇÃO DE ESPONJAS E FIOS DE AÇO NA REMOÇÃO DE COBRE DE EFLUENTES INDUSTRIAIS.
}

\author{
Luciane Pimentel Costa Monteiro ${ }^{1}$ \\ Fernando Benedicto Mainier²
}

\begin{abstract}
Resumo: Os processos de obtenção de cobre são, de maneira geral, fontes extremas de poluição ambiental e causadores de malefícios à saúde humana, devido à alta toxidez do elemento cobre e seus compostos. $\mathrm{Na}$ maioria desses processos, os efluentes gerados são ainda, bastante impregnados deste elemento, vindo a poluir o solo, as águas superficiais e corpos receptores. Além disso, quando se faz uso de algum processo de remoção do cobre dos efluentes industriais, a eficiência de eliminação do cobre e seus compostos presentes, não é suficiente para impedir que permaneçam elevadas concentraçôes deste contaminante na corrente fluida. Foram realizados estudos experimentais de adsorção com esponjas e fios de aço, agentes adsorventes não convencionais para íons $\mathrm{Cu}^{2+}$, em uma solução aquosa de sulfato de cobre, visando o levantamento de parâmetros como temperatura de operação, tempo de contato adsorvedor/adsorvido e agitação, necessários ao melhor desempenho desta adsorção, bem como a melhor área de adsorção do cobre pelos materiais testados. Os resultados da adsorção foram realizados através da análise em equipamento eletroanalisador de metais para o teor dos íons $\mathrm{Cu}^{2+}$ na solução resultante.
\end{abstract}

Palavras-chave: metais pesados, cobre, remoção de cobre, adsorção de cobre

\begin{abstract}
The copper processes production are generally sources of great environmental pollution. The copper element and its compounds are dangerous to the human healthy due to the high toxicity. The effluents originated in the processes contaminated with copper, pollutes the soil, surface waters and receptive bodies. Add to these problems, the remove processes of copper and its compounds are not efficient to guarantee the high concentrations of that contaminant in the fluid stream. Experiments of adsorption with steel sponges and wires, how non conventional adsorbent agents to the ions $\mathrm{Cu}^{2+}$ in aqueous solution were made with the objective to estimate unit operational parameters. The results of $\mathrm{Cu}^{2+}$ ions concentration were made with metals electro analyzer equipment in the result solution.
\end{abstract}

Key-words: heavy metals, copper, copper removal, copper adsorption

\section{INTRODUÇÃO}

Efluentes contendo metais como cádmio, cobre, chumbo e cromo exibem elevada biotoxicidade, em geral com efeitos acumulativos no bioma. A remediação de efluentes contaminados pode ser feita por vários processos de tratamento alternativos porém, as fontes de contaminação são extensas e variadas (FENG et all,2004).
Anualmente, cerca de 80.000 toneladas de cobre contaminam o planeta sendo que as fontes naturais representam 25\% deste contingente enquanto as antropogênicas $75 \%$.

Grandes fontes de contaminação por resíduos de cobre são as minerações, fundições de diversos tipos de ligas de cobre, o refino eletrolítico de cobre $\mathrm{e}$, as empresas que prestam serviços de galvanoplastia. Gunther (1998) avaliou, em suas pesquisas, os

\footnotetext{
1 Programa de Pós Graduação Eng. Química - UFF e-mail: lucianemonteiro@predialnet.com.br

2 Programa de Pós Graduação Eng. Química - UFF e-mail: fmainier@uol.com.br
} 
impactos ambientais provocados pelos efluentes provenientes dos processos de galvanoplastia das indústrias localizadas na região do Vale do Paraíba, Estado de São Paulo. Além disso, os efluentes de cobre quando associados ao cianeto podem causar, direta e indiretamente, contaminações ambientais de grandes proporçōes (MAINIER, 2002).

Existe grande perigo quando são utilizadas ligas de cobre nos diversos segmentos (bronze, latão, cupro-níquel), pois o processo corrosivo passa a ser responsável por contaminações nos processos de produção nas indústrias alimentícias e farmacêuticas.

Já, com relação às contaminações propriamente ditas provocadas por cobre, segundo Gaethe \& Chow (2003), o cobre, sob a forma de íons $\mathrm{Cu}^{+} \mathrm{e} \mathrm{Cu}^{2+}$, é um elemento traço essencial encontrado em pequenas quantidades em células e tecidos, sejam animais e vegetais.

No corpo humano, a absorção de cobre depende de vários fatores incluindo desde a forma química aos outros componentes dietéticos. A ingestão de cobre nos seres humanos está relacionada à ingestão acidental ou a contaminação através de bebidas e alimentos.

Trabalhos apresentados por Barceloux (1999) mostram relatos de contaminações por sulfato de cobre provocando doenças e distúrbios, tais como: sensações de vômitos, ardências, diarréia, danos renais e aumento da pressão arterial.

Segundo Pedrozo \& Lima (2001), os alimentos são mais prováveis de contaminação do que a água. Nos mamíferos, o cobre geralmente é absorvido no estômago e no intestino delgado, embora, somente uma pequena quantidade ingerida é solubilizada e absorvida no estômago.

A intoxicação aguda por cobre causa a erosão do epitélio gastrintestinal associado à necrose do fígado e dos rins. Além disso, o elemento cobre causa doenças ligadas à genética. Ao serem queimados resíduos com certos compostos de cobre têm-se as reações, a seguir (MONTEIRO,2007).

$$
\begin{aligned}
& \mathrm{Cu}_{2} \mathrm{~S}+2 \mathrm{O}_{2} \rightarrow 2 \mathrm{CuO}+\mathrm{SO}_{2} \\
& \mathrm{Cu}_{2} \mathrm{~S}+2 \mathrm{CuO} \rightarrow 4 \mathrm{Cu}+\mathrm{SO}_{2}
\end{aligned}
$$

\section{FUNDAMENTAÇÃO TEÓRICA}

O cobre é um metal de transição avermelhado, que apresenta alta condutibilidade elétri- ca e térmica, só superada pela da prata. É possível que o cobre tenha sido o metal mais antigo a ser utilizado, pois se têm encontrado objetos de cobre de 8.700 a.C. Pode ser encontrado em diversos minerais e pode ser encontrado nativo, na forma metálica, em alguns lugares. A figura 1, a seguir, apresenta o cobre em sua forma metálica (ICSG,2007).

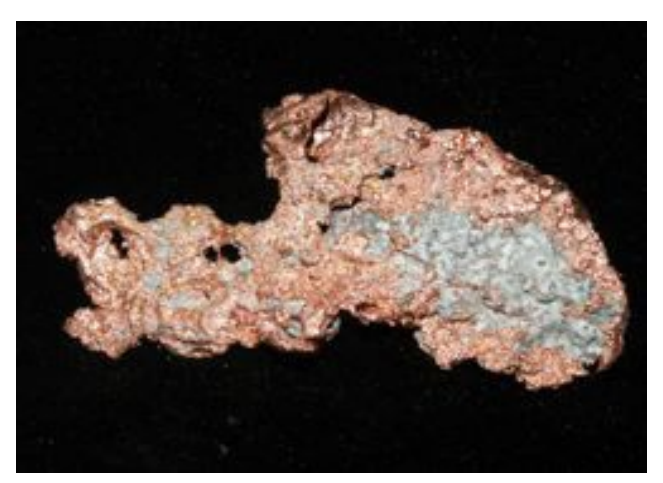

Figura 1 - cobre em sua forma metálica Fonte: Trzepizur, M. , 2009 - DICIONÁRIO LIVRE DE GEOCIÊNCIAS

$\mathrm{Na}$ maioria de seus compostos apresenta estados de oxidação baixos, sendo o mais comum $o+2$, ainda que existam alguns com estado de oxidação +1 . Exposto ao ar, a coloração vermelho salmão inicial torna-se vermelho violeta devido à formação do óxido cuproso $\left(\mathrm{Cu}_{2} \mathrm{O}\right)$ para enegrecer-se posteriormente devido à formação do óxido cúprico $(\mathrm{CuO})$. Exposto longamente ao ar úmido forma uma capa aderente e impermeável de carbonato básico de coloração verde, característica de seus sais, que é venenosa. Quando se utilizam caçarolas de cobre para a cocção de alimentos são freqüentes as intoxicações, devido à ação dos ácidos da comida que originam óxidos, contaminando os alimentos (BARCELOUX, 1999).

Os halogênios atacam com facilidade o cobre, especialmente em presença de umidade; no seco, o cloro e o bromo não produzem efeito e o flúor só o ataca a temperaturas superiores a $500^{\circ} \mathrm{C}$. Os oxiácidos atacam o cobre, com o efeito decapante para o (ácido sulfúrico) e, para dar-lhe brilho, (ácido nítrico). Com o enxofre forma um sulfeto $(\mathrm{CuS})$ de coloração branca (BARCELOUX,1999). 


\subsection{FONTES NATURAIS DE COBRE}

O cobre é amplamente distribuído na natureza no estado elementar, como sulfetos, arsenitos, cloretos e carbonatos. $\mathrm{Na}$ crosta terrestre apresenta uma abundância natural de $60 \mathrm{mg} / \mathrm{Kg}$ (60 ppm) e 2,5 x 10-4 mg/L nos mares. Ocorre em muitos minérios em forma de óxidos e sulfetos. A malaquita, a calcopirita e a calcocita são as principais fontes de cobre. Suas composições químicas apresentam-se na tabela 1 , a seguir. $\mathrm{O}$ conteúdo de cobre nos depósitos minerais varia de 0,5 a $5 \%$ em peso e, as rochas ígneas contêm $0,010 \%$ enquanto as rochas cristalinas contêm $0,0050 \%$ do peso (WHO,2000).

Tabela 1 - composição dos principais minérios de cobre

\begin{tabular}{|l|c|}
\hline Minério & Composição \\
\hline malaquita & $\mathrm{Cu}_{2} \mathrm{CO}_{3} \cdot \mathrm{Cu}(\mathrm{OH})_{2}$ \\
\hline calcopirita & $\mathrm{CuFeS}_{2}$ \\
\hline calcocita & $\mathrm{Cu}_{2} \mathrm{~S}$ \\
\hline
\end{tabular}

Fonte: Burgess, 1995

Apesar de ser um dos metais menos abundantes da crosta terrestre, é de fácil obtenção, apesar de laboriosa, devido à pobreza do metal nos minerais; se considera economicamente viável extraí-lo de um mineral com quantidades superiores a $0,5 \%$ de cobre e muito rentável a partir de $2,5 \%$ (WHO,2000).

\subsection{EXTRAÇÃO}

A obtenção do cobre começa com a extração do mineral. Esta pode ser realizada a céu aberto (a exploração mais comum), em galerias subterrâneas ou in situ, procedimento pouco usado, que consiste em injetar ácido sulfúrico na mina de cobre bombeando, posteriormente, para a superfície as soluções ácidas ricas em cobre. Já, o mineral extraído por métodos mecânicos, óxidos e sulfetos, é triturado obtendo-se um pó que contém usualmente menos que 1\% de cobre. Este deverá ser enriquecido ou concentrado obtendo-se uma pasta com aproximadamente $15 \%$ de cobre que, posteriormente, é secado. A partir deste ponto pode-se utilizar outros métodos (BURGESS,1995).
O mineral é transladado a um tanque de lixiviação no qual se injeta ácido sulfúrico diluído obtendo-se uma solução fraca de sulfato de cobre, da qual se obtém, por eletrólise, o cobre catodo (BURGESS,1995).

Com o mineral enriquecido prepara-se uma mistura, adicionado os fundentes necessários de base sílica para sulfetos e sulfetos para óxidos, que fundida, produz o cobre blister. Este é refinado através de procedimentos térmicos obtendo-se anodos de cobre que, por sua vez, se refinam por eletrólise usando-os junto a lâminas mãe de cobre como catodo em meio ácido. Da lama (subproduto da eletrólise) retira-se o ouro, a prata e a platina (BURGESS, 1995).

\subsection{TOXICIDADE}

Todos os compostos de cobre deveriam ser tratados como se fossem tóxicos, uma quantidade de $30 \mathrm{~g}$ de sulfato de cobre é potencialmente letal em humanos. O metal em pó é combustível, inalado pode provocar tosse, dor de cabeça e dor de garganta, recomenda-se evitar a exposição ocupacional e a utilização de protetores como óculos, luvas e máscaras. $\mathrm{O}$ valores limites ambientais são de $0,2 \mathrm{mg} / \mathrm{m}^{3}$ para os vapores e $1 \mathrm{mg} / \mathrm{m}^{3}$ para o pó e névoas. Reage com oxidantes fortes tais como cloratos, bromatos e iodatos, originando o perigo de explosões (WHO,1998).

A água, com conteúdo superiores a $1 \mathrm{mg} / \mathrm{L}$, pode contaminar com cobre as roupas e objetos lavados com ela, e conteúdos acima de $5 \mathrm{mg} / \mathrm{L}$ tornam a água colorida com sabor desagradável. A Organização Mundial da Saúde (OMS) no Guia para a qualidade da água potável recomenda um nível máximo de $2 \mathrm{mg} / \mathrm{L}$, mesmo valor adotado na União Européia. Nos Estados Unidos a Agência de Proteção Ambiental tem estabelecido um limite de 1,3 mg/L (WHO,1998).

\section{MÉTODOS DE REMOÇÃO DE METAIS PESADOS DE EFLUENTES INDUSTRIAIS}

Os resíduos contaminados por metais pesados são mais difíceis de serem tratados do que outros tipos de resíduos, necessitando na maioria dos casos, para adequação ambiental do efluente, de tratamentos mais específicos. O método de ajuste e aumento dos valores de contaminan- 
tes no efluente a ser tratado pode ser também utilizado para a remoção de metal pesado da solução, pois a presença de carbonato aumenta os valores de $\mathrm{pH}$, formando hidróxidos e carbonatos metálicos precipitados na massa líquida e retirados posteriormente por processo de filtração (FRANCISCHETTI,2004).

As empresas, de modo geral, têm adotado esse procedimento de formação de precipitados de metais pesados. No entanto, devido ao limite de solubilidade desses precipitados, poderão permanecer quantidades do metal na solução tratada em níveis superiores aos desejados. Além disso, este tratamento apresenta como grande desvantagem a formação de lodo galvânico, composto principalmente por metais pesados e agentes complexantes, sendo considerado um resíduo muito tóxico, não podendo ser descartado em aterro comum. Os efluentes líquidos ricos em metais pesados podem também ser tratados por meio de sistemas de eletrodeposição química. São mais favoráveis no sentido de que não formam lodo galvânico quando removem os metais pesados dos efluentes. A utilização industrial desse processo de recuperação, no entanto, apresenta problemas relativos ao custo e à disponibilidade de energia elétrica (FRANCISCHETTI, 2004).

Os processos de regeneração de metais pesados podem ser compostos de dois ou mais processos químicos conjugados. Tem sido muito utilizada a composição dos processos por troca iônica seguido do uso de célula de eletrodeposição. Já, nos processos de recuperação desses metais utilizando resinas trocadoras de íons, o custo torna-se muito elevado devido à aquisição da resina e posterior destruição. Esse processo, então, tem sido preferencialmente utilizado na retenção e regeneração de metais nobres tais como ouro, a prata, o rhódio e o paládio (FRANCISCHETTI, 2004).

Existem vários materiais adsorvedores nãoconvencionais de baixo custo que podem vir a viabilizar o uso do processo de adsorção no tratamento de descargas líquidas ricas em metais pesados como o cobre. A tabela 2, a seguir, demonstra a capacidade de adsorção de alguns materiais adsorvedores não-convencionais e sua capacidade de remoção de íons $\mathrm{Cu}^{2+}$.
Tabela 2 - Capacidade de remoção de íons $\mathrm{Cu}^{2+}$ utilizando alguns adsorventes a $25^{\circ} \mathrm{C}$

\begin{tabular}{|l|c|c|}
\hline Adsorv. & $\begin{array}{c}\text { Adsorção } \\
\text { Langmuir** } \\
\mathrm{mg} / \mathrm{g}\end{array}$ & $\begin{array}{c}\text { Adsorção } \\
\text { Freundlich** } \\
\mathrm{mg} / \mathrm{g}\end{array}$ \\
\hline Argila ativada & 0,665 & 0,235 \\
\hline Carvão ativado & 0,203 & 0,130 \\
\hline $\begin{array}{l}\text { Carvão } \\
\text { shungite* }\end{array}$ & 0,277 & 0,047 \\
\hline $\begin{array}{l}\text { Farelo de trigo } \\
\text { desid. } \\
\text { (pH = 5) }\end{array}$ & 51,5 & ------ \\
\hline quitosana & 53,20 & 13,17 \\
\hline Turfa & 26,06 & -------- \\
\hline arTiO 2 & ------- & 2,213 \\
\hline $\begin{array}{l}\text { Cinzas leves } \\
\text { (pH = 6) }\end{array}$ & 1,351 & ------ \\
\hline
\end{tabular}

Fonte: Francischetti, J. - Dissertação de Mestrado - dez/ 2004

* Carvão originário de uma rocha rara encontrada em uma região denominada Shunga na URSS.

** Modelos teóricos estudados

\section{EXPERIMENTOS DE ADSORÇÃO}

Os experimentos foram realizados, com o objetivo de adsorver o metal pesado cobre, representado por seus íons $\mathrm{Cu}^{2+}$, através da utilização de materiais adsorventes não convencionais, como a sucata de esponjas e fios de aço.

Para a realização dos testes de adsorção foi montada uma aparelhagem composta de um recipiente em acrílico com capacidade de $1,5 \mathrm{~L}$, com agitação, suportado em uma chapa elétrica para aquecimento controlado. Foi conectado também, um agitador mecânico para maior difusão dos íons cobre na massa líquida contendo o material adsorvente.

Para controle da temperatura foi utilizado um termômetro com escala de $0-100^{\circ} \mathrm{C}$, introduzido na massa reacional de $400 \mathrm{~mL}$ constituída de $1 \mathrm{~g}$ de sal para $400 \mathrm{~mL}$ de água deionizada. Os íons $\mathrm{Cu}^{2+}$ foram representados na forma do sal $\mathrm{Cu}_{2}\left(\mathrm{SO}_{4}\right)_{3}$. A figura 2 , a seguir, apresenta o esquema da aparelhagem utilizada. 


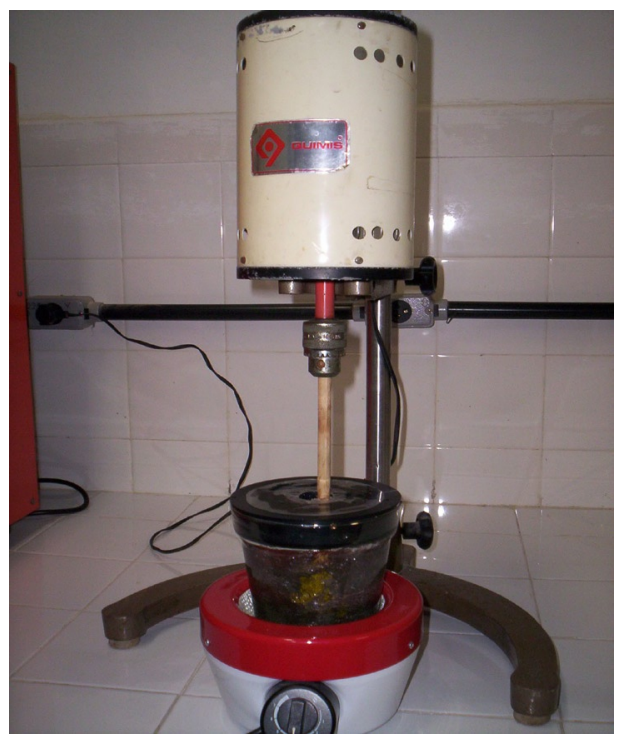

Figura 2 - Aparelhagem utilizada nos experimentos

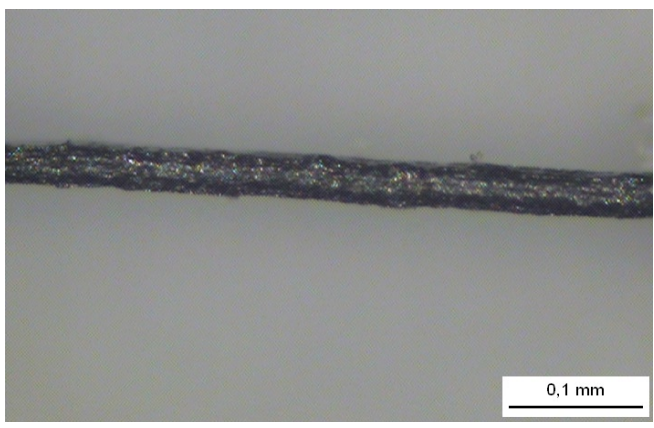

Fio 1 / parte 1

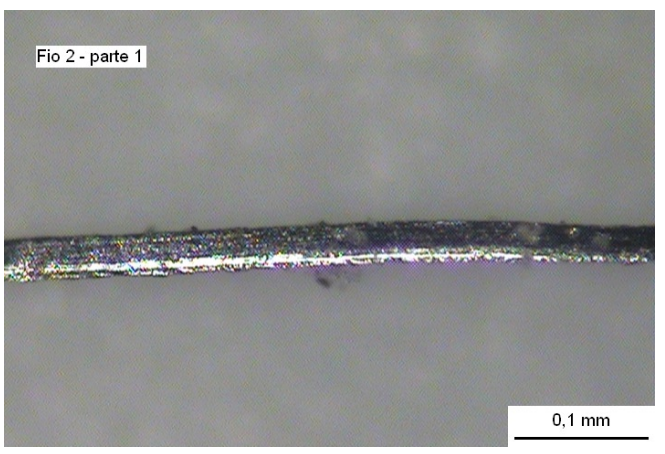

Fio 2 parte 1

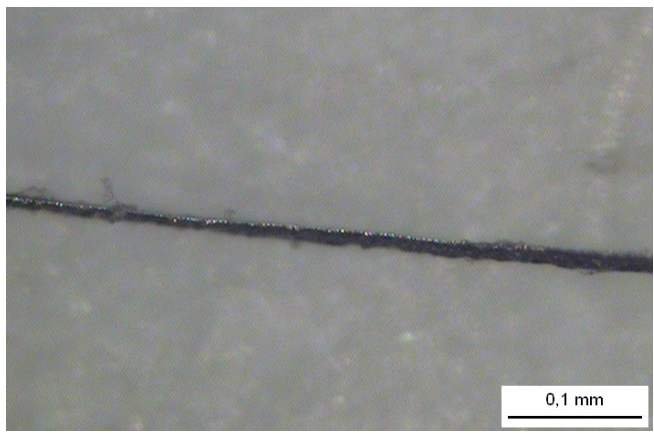

Fio 3 / parte 1
As quantidades de material adsorvente, utilizadas nos experimentos, foram mantidas para todos os três casos (esponja e fios de aço) e, a realização dos experimentos foi efetuada com valores de temperatura, tempo de reação e concentração de íons $\mathrm{Cu}^{2+}$ e íons $\mathrm{Fe}^{2+}$ fixos, porém variando-se o adsorvente utilizado. A figura 3, a seguir, apresenta fotos da esponja de aço utilizada, obtidas por microscopia eletrônica, em microscópio eletrônico com objetiva de alcance de 10X. Neste caso, foram tomadas três amostras do fio e lidos valores que foram corrigidos em escala. Para cada $0,1 \mathrm{~mm}$ da leitura microscópica o valor lido por medidores métricos convencionais em papel (régua, escala) é corrigido multiplicando-se por 35 vezes o resultado. Os demais arames de aço utilizados nos experimentos tiveram os valores de seus diâmetros medidos com paquímetro.

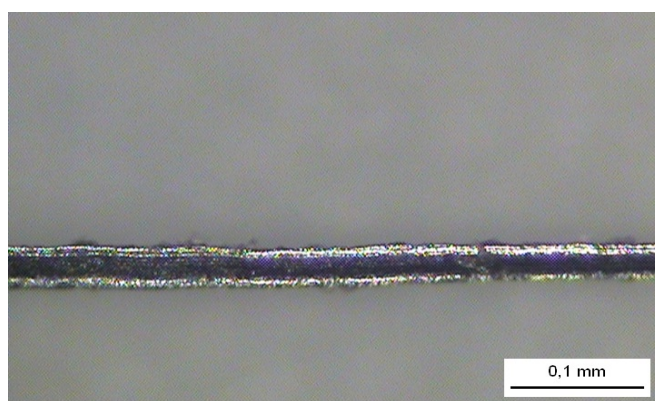

Fio $1 /$ parte 2

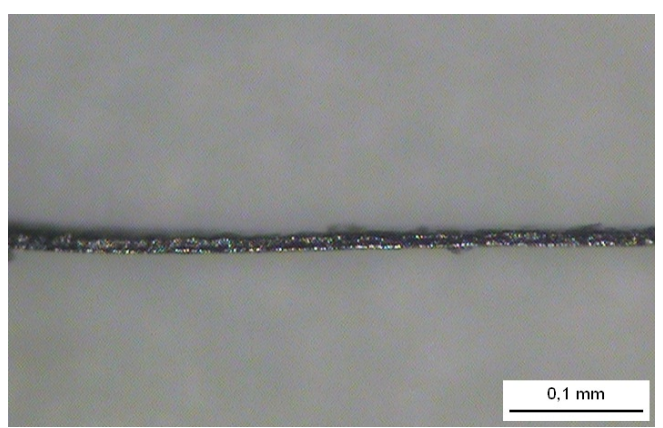

Fio 2 / parte 2

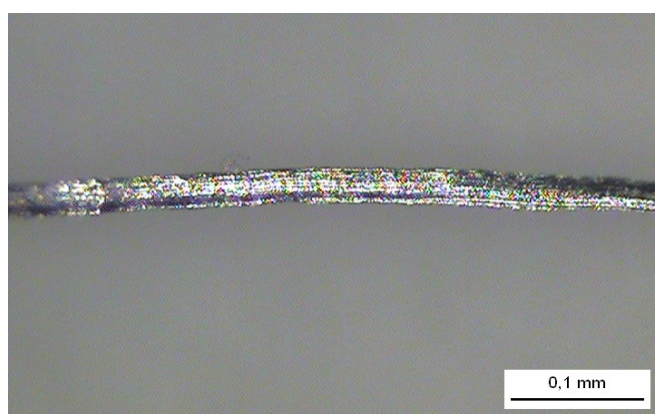

Fio 3 / parte 2

Figura 3 - Fios de esponja de aço - medição de espessura por microscopia ótica. Medidas em microscópio óptico com objetiva de 10X - Fotos com escala real 
Em seguida à pesagem do material adsorvente, foi realizado aquecimento do meio reacional até a temperatura de $40^{\circ} \mathrm{C}$, adicionando-se posteriormente o sal $\left(\mathrm{Cu}_{2} \mathrm{SO}_{4}\right)_{3}$ em quantidades estequiométricas. Foi dado, então, início à reação com agitação do meio em presença da solução de $\mathrm{Cu}^{2+}$ e material adsorvente durante o período aproximado de 15 minutos. Foram colhidas amostras da solução resultante, previamente filtrada, para retirada de algum material sobrenadante, proveniente da reação de redução do cobre pelo ferro.
A tabela 3, a seguir, apresenta as características do material adsorvente utilizado nos experimentos.

Foram feitas análises, em aparelho Eletroanalisador de Metais, da concentração de íons $\mathrm{Cu}^{2+}$ na solução resultante, visando medir a eficiência de remoção pela esponja de aço e fios de arame, conforme se verifica na tabela 4, a seguir. $\mathrm{O}$ que se objetivou foi a verificação da influência da área do adsorvente no processo de remoção dos íons cobre da solução em estudo. Os resultados das análises se encontram representados nas figuras 4,5 e 6, a seguir.

Tabela 3 - Características do Material Adsorvente Utilizado nos Experimentos

\begin{tabular}{|c|c|c|c|}
\hline Material & $\begin{array}{c}\text { Diâmetro } \\
(\mathrm{mm})\end{array}$ & $\begin{array}{c}\text { Área Contato no meio reacional }\left(\mathrm{mm}^{2}\right) \\
\text { para comprimento de 100mm }\end{array}$ & $\begin{array}{c}\text { Massa Fé2+ } \\
(\mathrm{mg})\end{array}$ \\
\hline $\begin{array}{c}\text { Adsorvente 01 } \\
\text { (lã-de-aço) }\end{array}$ & 0,026 & 8,16 & 225 \\
\hline $\begin{array}{c}\text { Adsorvente 02 } \\
\text { (arame mais fino) }\end{array}$ & 0,55 & 172,7 & 225 \\
\hline $\begin{array}{c}\text { Adsorvente 03 } \\
\text { (arame mais grosso) }\end{array}$ & 2,80 & 879,2 & 225 \\
\hline
\end{tabular}

Tabela 4 - Rendimento de Remoção de Íons $\mathrm{Cu}^{2+}$ Pelos Agentes Adsorvedores

\begin{tabular}{|c|c|c|c|}
\hline Agente & $\begin{array}{c}\text { Massa } \mathrm{Cu}^{2+} \text { Inicial } \\
(\mathrm{ppm})\end{array}$ & $\begin{array}{c}\text { Massa } \mathrm{Cu}^{2+} \text { Final } \\
(\mathrm{ppm})\end{array}$ & $\begin{array}{c}\text { Rendimento de remoção de } \\
\mathrm{Cu}^{2+} \text { da solução (\%) }\end{array}$ \\
\hline Adsorvente 01 & 636 & 150 & 74,6 \\
\hline Adsorvente 02 & 636 & 580 & 8,8 \\
\hline Adsorvente 03 & 636 & 570 & 10,37 \\
\hline
\end{tabular}
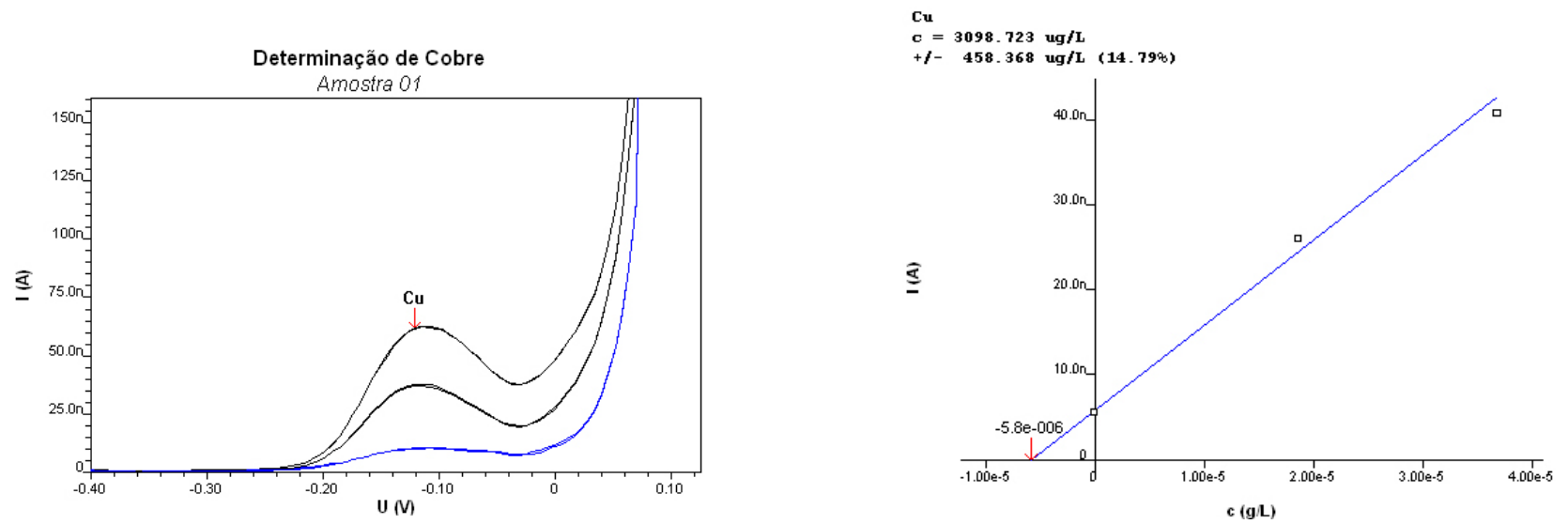

Figura 4 - Resultados da amostra 01: esponjas de aço 

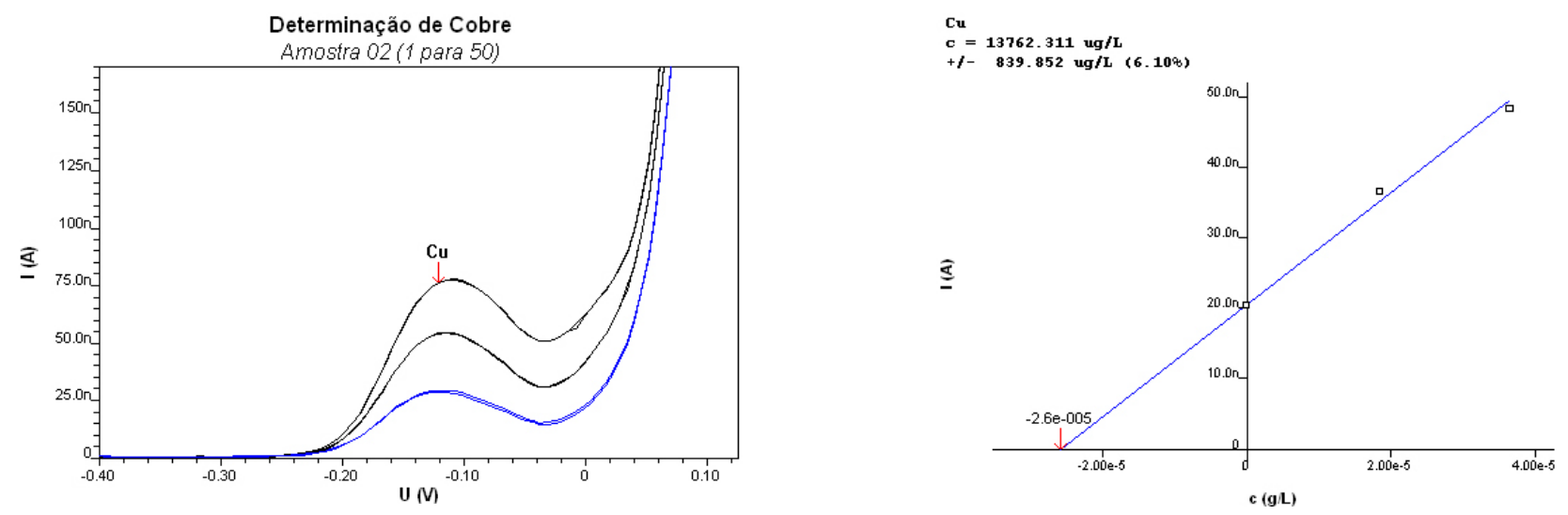

Figura 5 - Resultados da amostra 02: arame de aço mais fino
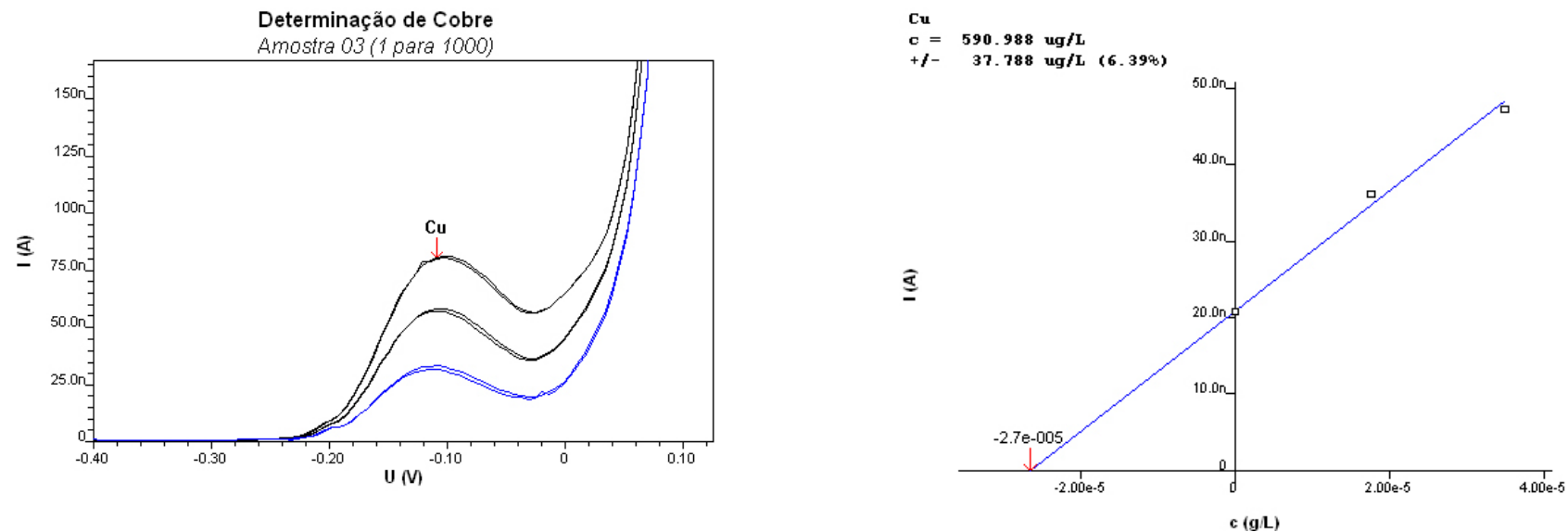

Figura 6 - Resultados da amostra 03: arame de aço mais grosso

\section{CONCLUSÔES}

- A esponja de aço representa adsorvedor não convencional eficaz para remoção de cobre na forma de seus íons $\mathrm{Cu}^{2+}$ em uma solução de sulfato de cobre.

- Não se pode concluir que a área de contato do material adsorvedor seja determinante na remoção de íons cobre da solução de sulfato de cobre.

- Nos experimentos, observa-se uma maior adsorção de íons cobre pela esponja de aço, o que nos leva a concluir que o volume, distribuição do material e as propriedades físicas e químicas são características determinantes para o bom desempenho do material adsorvedor.

- Nos experimentos para remoção de cobre com esponjas e fios de aço pode-se aliar dois tipos de resultados, tendo vantagens em relação a outros processos de remoção de metais: a técnica de adsorção e, a reação de redução do cobre pelo ferro, além dos prováveis fenômenos de precipitação.

- Esponjas de aço com diâmetros mais finos apresentaram maior capacidade de remoção do cobre, tendo em vista o rendimento de adsorção de cobre para os demais fios de aço de diâmetros maiores.

- Outros equipamentos, bem como condições experimentais, devem ser testados com o fim de se chegar ao projeto mais adequado para a separação do cobre e outros metais dos efluentes industriais.

- Esses experimentos devem ser estendidos para outros materiais, ditos adsorventes não convencionais, com o fim de reciclar e reaproveitar materiais tóxicos inservíveis, descartados na forma de seus compostos, sem qualquer critério, no meio ambiente. 
- Faz-se necessária a realização de estudos de adsorção para a remoção de outros metais pesados de efluentes industriais, tais como cádmio, chumbo e níquel, que hoje tem destinação parecida com a dos efluentes contendo cobre.

- Além da importância que a adsorção de metais pesados representa ao meio ambiente e ao ser humano, vale ressaltar não só o retorno financeiro com a venda do metal recuperado, como a preservação de recursos naturais. No caso do cobre, em especial, é um metal de grande importância industrial devido às suas múltiplas aplicações no nosso dia a dia, destacando seu valor nos mercados nacional e internacional.

- O reaproveitamento do cobre é de suma importância a fim de que consigamos estender o prazo de disponibilidade de recurso natural tão precioso ao homem e ao planeta.

\section{REFERÊNCIAS}

BAPTISTA NETO, J.A., SMITH, B.J., Mc ALISTEN, J.J. Heavy metal concentrations in surface sediments in a nearshore environment, Jurujuba sound, Southeast brazil. Environmental Pollution, v. 109, p1-9,2000.

BARCELOUX, D.G. Copper. Clin Toxicol. V.37 n2 p.217 - 230, 1999.

BURGESS,W.A. Identificação de possíveis riscos à saúde do trabalhador nos diversos processos industriais. 2 ed. Belo Horizonte: Ergo, 1995.

DICIONÁRIO LIVRE DE GEOCIÊNCIAS, 1999 - WIKIPEDIA.
FENG ET alli. Adsorption of lead and Mercury by Rice husk ash. Journal of Colloid an Interface Science, v.278, no1, p.1-8,2004.

FRANCISCHETTI, J. Dissertação de Mestrado: Remoção de Metais Pesados em Efluentes Líquidos Através da Filtração Adsortiva. Universidade Federal de Santa Catarina. Florianópolis - SC - dez/2004.

GAETHE ,L.M. \& CHOW,C.K., Copper toxicity, oxidative stress and antioxidant nutrients, Toxicology ( Elsevier),189, p.147-163, 2003.

GUNTHER, W.M.R. Contaminação ambiental por disposição inadequada de resíduos industriais contendo metais pesados: estudo de caso. Tese de Doutorado - Faculdade de saúde Pública, Universidade de São Paulo, São Paulo, 1998.

ICSG - World Copper Factbook, 2007.

KEEN,C.L.,URIU-HARE,J.Y.; ITAWK,S.N.; JAN KOWSKI,M.A.;DASTON,G.P.; KWIK-. KURJKIAN, R. Metal contamination in the Republic of America. Environmental Management, v.2, n.5, p.447-487, 2000.

MAINIER,F.B. As contaminações provocadas por cianeto no meio ambiente. In: Anaiis Congresso Nacional de Excelência em Gestão, UFF, Niterói, CD-ROM , 8p,2002.

MONTEIRO,L.P.C. Tese de Doutorado. Avaliação da queima de resíduos industriais em fornos de clínquer: visão sob o prisma da educação ambiental, out/2007.

WHO - World Health Organization Copper. Geneva: Environmental Health Criteria 